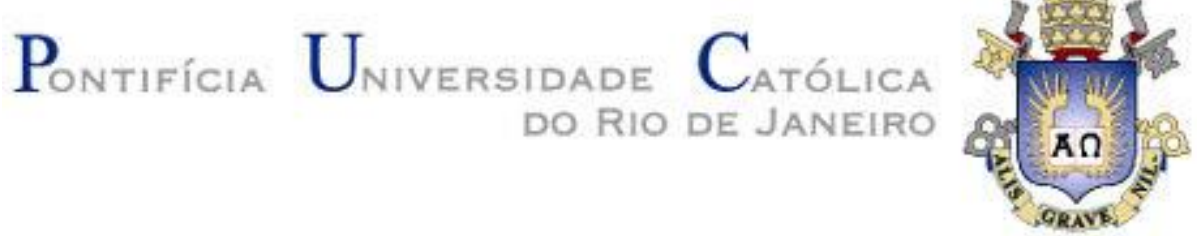

Rafael de Abreu Ferraz

Paisagem e Patrimônio: a atividade turística no município de Vassouras (RJ)

Dissertação apresentada como requisito parcial para obtenção do grau de Mestre pelo Programa de PósGraduação em Geografia, do Departamento de Geografia da PUC-Rio.

Orientador: João Rua

Co-orientador: Glaucio José Marafon

Rio de Janeiro Junho de 2011 


\section{Rafael de Abreu Ferraz}

Paisagem e Patrimônio: a atividade turística no município de Vassouras (RJ)

Dissertação apresentada como requisito parcial para obtenção do grau de Mestre pelo Programa de Pósgraduação em Geografia do Departamento de Geografia do Centro de Ciências Sociais da PUC-Rio. Aprovada pela Comissão Examinadora abaixo assinada.

Prof. João Rua

Orientador

Departamento de Geografia - PUC-Rio

\section{Prof. Gláucio José Marafon \\ Co-Orientador \\ Instituto de Geografia - UERJ}

Prof. Alvaro Henrique de Souza Ferreira

Departamento de Geografia - PUC-Rio

Prof. Miguel Ângelo Campos Ribeiro Instituto de Geografia - UERJ

Profa Mônica Herz

Vice-Decana de Pós-Graduação do Centro de

Ciências Sociais - PUC-Rio

Rio de Janeiro, 09 de junho de 2011 
Todos os direitos reservados. É proibida a reprodução total ou parcial do trabalho sem autorização da universidade, da autora e do orientador.

Rafael de Abreu Ferraz

Graduou-se em Geografia pela Universidade do Estado do Rio de Janeiro - UERJ (2007). Possui Especialização em Políticas Territoriais no Estado do Rio de janeiro - UERJ (2009). Professor das redes Municipais de Angra dos Reis e do Rio de Janeiro.

Ficha Catalográfica

Ferraz Rafael de Abreu

Paisagem e Patrimônio: a atividade turística no município de Vassouras (RJ) / Rafael de Abreu Ferraz ; orientador: João Rua ; co-orientador: Glaucio José Marafon - 2011. 103 f. : il.(color.) ; $30 \mathrm{~cm}$

Dissertação (mestrado)-Pontifícia Universidade Católica do Rio de Janeiro, Departamento de Geografia, 2011.

Inclui bibliografia

1. Geografia - Teses. 2. Espaço. 3. Paisagem. 4. Turismo. 5. Patrimônio. I. Rua, João. II. Marafon, Glaucio José. III. Pontifícia Universidade Católica do Rio de Janeiro. Departamento de Geografia. IV. Título.

CDD: 910 


\section{Agradecimentos}

Não poderia deixar de dividir a conclusão do presente trabalho com as pessoas que ao longo da minha trajetória de vida, em especial nos últimos dois anos, colaboraram para que esse momento se tornasse realidade. Mesmo correndo o risco de esquecer alguns nomes - e, por isso, me desculpo desde já -, faço questão de mencioná-los, externando um fraterno sentimento de gratidão.

Agradeço primeiramente a Deus, pelas oportunidades e desafios colocados em minha vida. É no Grande Arquiteto do universo que encontro a paz e a força para prosseguir nos momentos mais difíceis. A execução deste trabalho clamou muito esforço, dedicação e paciência, em um momento em que o corpo pedia descanso, a alma, serenidade, e a mente, luz!

Aos meus pais, que tanto amo, Janice e José Celso, sem os quais jamais teria sido possível essa experiência. Que vocês, apoiados em Deus, continuem tendo coragem para lutar! Levarei comigo por toda minha vida a imagem do exemplo de caráter, de honestidade e de sacrifício dispendido em prol de minha formação. Obrigado por tudo o que sou. Amo muito vocês!

À minha amada, Márcia Helena, agradeço, mais uma vez, pelas palavras de ânimo e conforto nos momentos mais difíceis. Obrigado pelo carinho, amor, atenção, paciência e pelo ombro amigo. Não poderia deixar de lembrar suas palavras "levanta essa cabeça e segue!" Sem dúvida, elas foram de grande estímulo.

Ao professor Orientador João Rua, reitero minhas palavras de agradecimento por sua generosidade em dividir seu vasto conhecimento; por ter abraçado o desafio desta orientação; pelas sugestões que nortearam minha caminhada acadêmica; pelo exemplo de professor e profissional de excelência notória, no árduo e difícil exercício do que representam as funções do magistério e nas quais procuro espelhar-me. Obrigado também por despertar-me a necessidade de pensar a respeito de minhas auto cobranças, do excesso de exigência com que me guio e por pensar, aceitar e saber lidar com as reviravoltas da vida. Por mais que exista um planejamento, precisamos aceitar que sempre existirão os fatos não planejados. Obrigado por todo o tempo que despendeu com minhas dúvidas e questões. Obrigado pelo conforto e carinho com que sempre me tratou desde os tempos de NEGEF pela amizade e pelo incentivo na busca do ingresso ao Mestrado. Devo muito a você, Professor João Rua, a conclusão deste trabalho.

Ao Professor Coorientador Gláucio José Marafon pela oportunidade que me foi dada por ocasião de meu ingresso no NEGEF. Graças a essa oportunidade, tornouse possível alçar novos voos; pelo incentivo para o ingresso no Mestrado; pela convivência fraterna ao longo dos últimos nove anos e, fundamentalmente, pelo exemplo de profissional dedicado que sempre foi e que também contribuiu para a formação do profissional que hoje sou.

Ao professor Miguel Ângelo Ribeiro, antes de tudo, por ter aceitado o convite para compor mais esta banca. Obrigado por sua participação em meu exame de qualificação e pelo estímulo na realização da presente dissertação. Reitero as 
palavras já colocadas em momentos anteriores. Obrigado pelo compromisso com a ética, com a disciplina na observância de horários, prazos e pelo respeito ao outro. Sobretudo, obrigado pela torcida e pelo carinho com o qual sempre me tratou. Muitas dessas qualidades a que fiz referência e que ficaram impressas em minha trajetória acadêmica também são facilmente destacadas no caráter dos professores Gláucio Marafon e João Rua.

Ao Professor Álvaro Henrique Ferreira por também ter aceitado o convite de participar dessa banca e pela oportunidade de muito ter aprendido com suas preleções e orientação na matéria Estágio à Docência.

Aos demais professores do Programa de Pós-Graduação da PUC-Rio, por também colaborarem para o processo de meu amadurecimento intelectual. Não poderia deixar de lembrar-me das aulas dos Professores Augusto César Pinheiro, Rogério Ribeiro de Oliveira e Ivaldo Lima.

Ao pessoal do corpo administrativo da Instituição, Márcia e Edna (Secretaria), pelo tratamento carinhoso, solicitude e cordialidade diárias.

Aos colegas e amigos de turma que me propiciaram diversos debates e com os quais, portanto, aprendi muito. Em especial ao amigo Antônio Lopes, pelas conversas, pelos momentos de desabafo mútuo e pelas palavras de incentivo.

Aos colegas de trabalho Fátima Monteiro, Eliane, Leila Haddad, Luís Cláudio, Gleiber, Sandra Cardoso, Patrícia Magno, Renata Moreira, Rosana pela forte torcida pelo sucesso na conclusão do presente trabalho.

Aos colegas do Negef com quem convivi, conversei, troquei conhecimentos e estabeleci laços de amizade nos anos que nortearam a minha vida acadêmica ainda nos tempos da Uerj. Momentos estes compartilhados dentro ou fora do Negef, nos trabalhos de campo, nos eventos, projetos etc.

À amiga Renata da Silva Correa pela ajuda imprescindível na confecção do mapa que compõem o presente trabalho.

À Pontifícia Universidade Católica do Rio de Janeiro que me proporcionou a oportunidade de estudo em uma instituição de excelência e qualidade notória.

A todos que de alguma forma contribuíram para o meu crescimento enquanto homem, cidadão e ser humano. Meu muito obrigado. 


\section{Resumo}

Ferraz Rafael de Abreu. Mattos, Rua, João. Paisagem e patrimônio: a atividade turística no município de Vassouras (RJ). Rio de Janeiro, 2011. 103p. Dissertação de Mestrado - Departamento de Geografia, Pontifícia Universidade Católica do Rio de Janeiro.

O presente trabalho tem por finalidade aprofundar os estudos referentes às transformações espaciais do rural e do urbano fluminenses a partir da valorização da paisagem e do patrimônio exemplificados nos projetos ou intenções de desenvolvimento do turismo no município de Vassouras - município localizado na região do Médio Paraíba. As repercussões espaciais, sociais e políticas desse processo de valorização e da crescente urbanização do interior fluminense vêm mudando as formas, funções e estruturas de vastas áreas do Estado do Rio de Janeiro. Tomaremos o município de Vassouras como um exemplo dessas mudanças. Compreender as alterações pelas quais o rural e o urbano fluminenses vêm passando, porque inseridas em um movimento global de mudanças intensificadas a partir da segunda metade do século XX, significa compreender os modelos ou períodos de desenvolvimento, sendo fundamental trazer para o seio e trabalho os conceitos de espaço, paisagem, patrimônio e turismo rural. Neste contexto, os movimentos atuais de mudança espacial ocorridos em Vassouras são demonstrativos das transformações que marcam as regiões tradicionais em sua inserção nas novas interações, definidas pela lógica do desenvolvimento desigual e combinado. A escala é, portanto, também um conceito a ser valorizado na execução desta dissertação, uma vez que buscamos desenvolver este trabalho a partir de Vassouras, sem deixar de refletir em outras escalas, numa relação que perpassa do local ao global, em uma perspectiva de, ao final do trabalho, refletir de maneira a trazer para o centro da discussão a transescalaridade e a multidimensionalidade do espaço em questão.

\section{Palavras-chaves}

Espaço; Paisagem; Vassouras; Turismo e Patrimônio. 


\section{Résumé}

Ferraz Rafael de Abreu. Mattos, Rua, João. (Advisor) Paysage et Patrimoine: l'activité touristique dans la municipalité de Vassouras (RJ). Rio de Janeiro, 2011. 103p. Dissertation de Mastére - Departamento de Geografia, Pontifícia Universidade Católica do Rio de Janeiro.

Cette étude vise à approfondir les études sur les transformations spatiales des populations rurales et urbaines de Fluminense, en particulier l'appréciation du paysage et du patrimoine illustré par des dessins ou des intentions de développer le tourisme dans la ville de Vassouras - commune située dans le Médio Paraíba dont les répercussions spatiales, les politiques sociales et de l'urbanisation croissante modifient l'intérieur de l'État en fait, les fonctions et structures de vastes zones de l'État de Rio de Janeiro. Comprendre les changements que les zones rurales et urbaines de Rio ont vécu, qui est entré dans un mouvement mondial pour le changement s'est intensifiée après la seconde moitié du XX e siècle moyens de comprendre les modèles ou les périodes de développement est fondamentale pour permettre ce travail dans le concept de l'espace paysage, le patrimoine et le tourisme rural. Dans cette étape, les mouvements actuels de la transformation de l'espace s'est produite dans balais sont la preuve des changements qui marquent les zones traditionnelles de leur inclusion dans de nouvelles interactions, définie par la logique du développement inégal et combiné. L'échelle est donc aussi un concept à être évalués dans la mise en œuvre de cette thèse, que nous cherchons à développer ce travail de balais tout en réfléchissant à d'autres échelles dans une relation qui imprègne du local au global, du point de vue la fin des travaux reflètent une façon d'amener le centre de la transescalaridade discussion et la multidimensionnalité de l'espace en question, dont la géographie de Rio n'a pas encore été tissé en particulier dans le domaine des relations entre la capitale et l'intérieur, ce qui indique que les trajectoires de ces espaces et leur leurs identités ne sont pas encore consolidés ou sont en processus de (re) construction comme un élément supplémentaire qui justifie l'importance de ce travail.

\section{Mots clés:}

Espace, Paysage, Vassouras, Tourisme et Patrimoine. 


\section{Sumário}

Introdução

1. O conceito de espaço e sua multidimensionalidade como elemento de compreensão dos espaços urbanos e rurais

1.1. Transformações espaciais no Estado do Rio de Janeiro e a (re)estruturação do espaço: o território do Vale do Ciclo do Café Fluminense no contexto de relações entre o rural e o urbano

1.2. O processo de desenvolvimento do território do Vale do Ciclo do Café: representações a partir de Vassouras

2. Paisagem, patrimônio, turismo e desenvolvimento

39

2.1. Turismo e desenvolvimento no Brasil e a valorização do rural

39

2.2. A valorização da natureza através do turismo: a mercadoria verde $\quad 44$

2.3. Desenvolvimento e potencialidades do turismo em Vassouras através da paisagem e do patrimônio

50

2.4. Debate recente a respeito do patrimônio: globalização, patrimônio e Identidade

58

2.5. A revalorização do conceito de paisagem

62

2.6. Pinturas de paisagem como elementos de representação do espaço de Vassouras

2.7. Paisagem, percepção, possibilidades de diferentes olhares sobre o Espaço

2.8. Paisagem marca e paisagem matriz: a importância da Praça Barão de Campo Belo enquanto expressão da identidade cultural do município de Vassouras

3. Transformações e interações espaciais no município de Vassouras

3.1. Vassouras e as novas possibilidades de desenvolvimento

4. Conclusão 


\section{Lista de figuras}

Figura 1 - Mapa do Estado do Rio de Janeiro 18

Figura 2 - Reforma do Palácio do Barão do Itambé 56

Figura 3 - Palácio Barão do Itambé 57

Figura 4 - Praça Barão de Campo Belo 72

Figura 5 - Comércio da Rua da "Broadway" 79

Figura 6 - Comércio da Rua da "Broadway" 80 


\section{Abreviaturas e siglas}

Conciclo - Conselho de Turismo da região do Ciclo do Café

Embrapa - Empresa Brasileira de Pesquisa Agropecuária

Embratur - Empresa Brasileira de Turismo

IBGE - Instituto Brasileiro de Geografia e Estatística

IPHAN - Instituto do Patrimônio Histórico e Artístico Nacional

NEGEF - Nucleo de Estudos de Geografia Fluminense

Preservale - Instituto de Preservação e Desenvolvimento do Vale do Paraíba

SEBRAE - Serviço Brasileiro de Apoio às Micro e Pequenos Empresas

TurisRio - Empresa de Turismo do Estado do Rio de Janeiro

UERJ - Universidade do Estado do Rio de Janeiro

UNESCO - United Nations Educational Scientific and Cultura Organizacional (Organização das Nações Unidas para a educação, a ciência e a cultura)

UFRJ - Universidade Federal do Rio de Janeiro 